\title{
Analisis Degradasi Performa Marka Jalan Thermoplastik pada Jalan Tol
}

\author{
Yogi Oktopianto ${ }^{1, *}$, Rukman $^{1}$ \\ Program Studi Manajemen Keselamatan Transportasi Jalan, Politeknik Keselamatan Transportasi Jalan, Tegal ${ }^{1}$ \\ Koresponden*, Email: yogi.oktopianto@pktj.ac.id
}

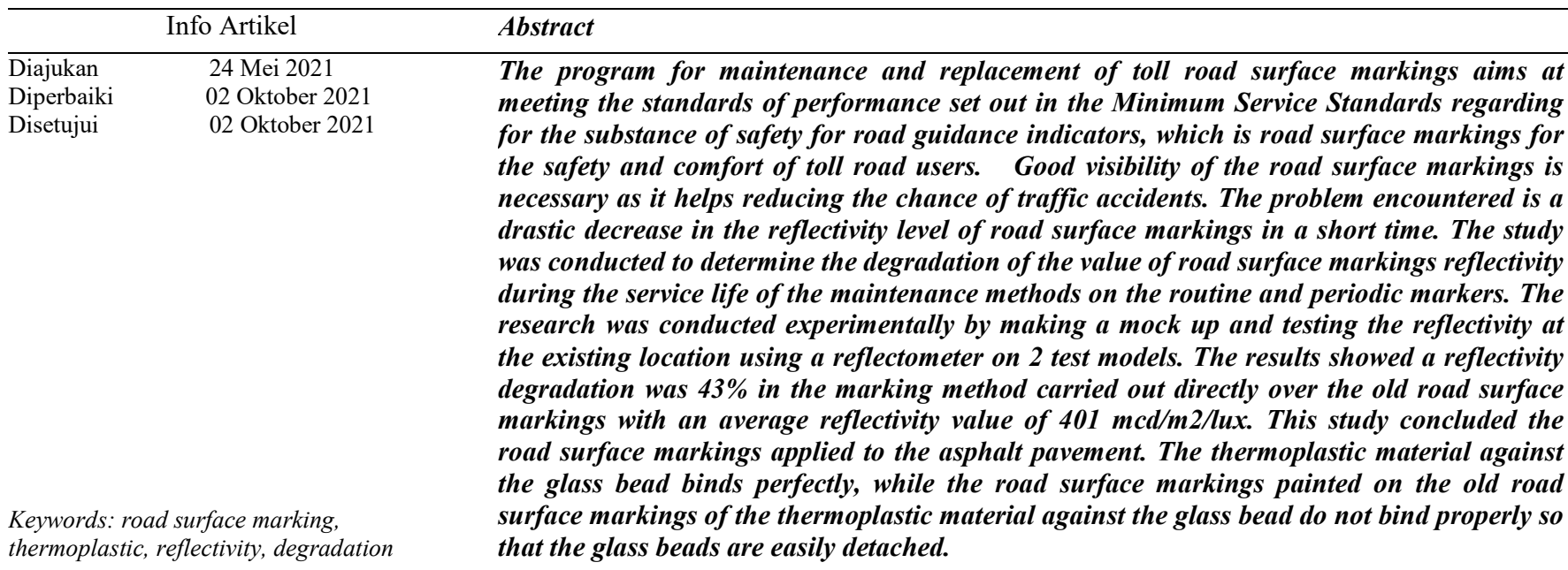

\begin{abstract}
Abstrak
Program pemeliharaan dan penggantian marka jalan tol bertujuan untuk memenuhi standar performa yang ditetapkan dalam Standar Pelayanan Minimal substansi keselamatan indikator petunjuk jalan yaitu marka jalan untuk keselamatan dan kenyamanan pengguna jalan tol. Visibilitas yang baik dari marka diperlukan karena membantu mengurangi kemungkinan kecelakaan lalu lintas. Permasalahan yang dihadapi terjadi penurunan tingkat reflektifitas marka jalan drastis dalam waktu singkat. Penelitian dilakukan untuk mengetahui degradasi nilai reflektifitas marka jalan pada masa layan terhadap metode pemeliharaan pada marka rutin maupun periodik. Penelitian dilakukan secara eksperimental dengan membuat mockup dan pengujian reflektifitas pada lokasi eksisting dengan menggunakan alat reflektometer terhadap 2 model pengujian. Hasil penelitian menunjukkan degradasi reflektifitas sebesar $43 \%$ pada metode penggelaran marka yang dilakukan langsung diatas marka lama dengan nilai reflektifitas rata-rata $401 \mathrm{mcd} / \mathrm{m} 2 / \mathrm{lux}$. Penelitian ini menyimpulkan marka jalan yang diaplikasikan di atas perkerasan aspal, material thermoplastik terhadap glass bead mengikat dengan sempurna, sedangkan marka jalan dicat di atas marka lama material thermoplastik terhadap glass bead tidak mengikat dengan baik sehingga glass bead mudah terlepas.
\end{abstract}

Kata kunci: marka jalan,
reflektifitas, degradasi

yang vital disektor transportasi. Volume lalu lintas, panjang

\section{Pendahuluan}

Marka jalan yang baik memberikan visibilitas yang baik untuk lalu lintas, sedangkan marka jalan yang buruk dapat mempengaruhi operasi lalu lintas di jalan tol. Berkendara dengan aman di malam hari membutuhkan rambu-rambu jalan yang harus dipantulkan untuk membantu pengemudi menavigasi dalam kondisi visibilitas rendah. Reflektifitas marka jalan adalah properti yang mengukur kemampuan tanda untuk memantulkan cahaya dari lampu ke mata pengemudi. Visibilitas yang baik dari marka diperlukan karena membantu mengurangi kemungkinan kecelakaan lalu lintas. Masalah kecelakaan lalu lintas menjadi suatu hal jalan, jumlah titik akses dan kecepatan lalu lintas memiliki pengaruh yang signifikan penyebab kecelakaan [1]. Jika volume lalu lintas meningkat dua kali lipat dari sebelumnya, jumlah kecelakaan akan meningkat sebesar 32,5\% per tahun [2]. Berbagai pengembangan model prediksi kecelakaan dalam perencanaan dan pelaksanaan program keselamatan jalan dikembangkan untuk mengurangi kecelakaan seperti Generalized Additive Models [3]. Tingginya angka kecelakaan dipengaruhi oleh kecepatan kendaraan persentil 85 melebihi batas kecepatan $40 \mathrm{~km}$ per jam [4]. Disisi lain perlengkapan jalan yang tidak jelas seperti reflektifitas 
marka menjadi faktor penyumbang kecelakaan bagi pengendara dimalam hari. Masalah kecelakaan lalu lintas perlu dilakukan kajian terhadapnya, baik mengenai penyebab, akibat, dan penanganannya [5].

Permasalahan yang dihadapi adalah terjadi penurunan reflektifitas melebihi batas yang diizinkan pada saat masa layan sehingga berisiko bagi pengguna jalan. Pada usia 1 tahun nilai eksisting reflektifitas rata-rata $183 \mathrm{mcd} / \mathrm{m} 2 / \mathrm{lux}$, ini berada di bawah spesifikasi standar reflektifitas minimal $250 \mathrm{mcd} / \mathrm{m} 2 / \mathrm{lux}$ untuk jalan tol pada akhir tahun ke-1. Terjadi penurunan nilai reflektifitas marka jalan sebesar $44 \%$ selama satu tahun [6].

Beberapa penelitian telah dikembangkan baik teknis maupun non teknis seperti persepsi publik tentang tingkat kecerahan marka jalan. Departemen Perhubungan Minnesota (MnDOT) melakukan penelitian untuk menetapkan nilai ambang reflektifitas untuk digunakan dalam program manajemen marka jalan, sebagai hasil dari proyek riset, MnDOT akan menggunakan $120 \mathrm{mcd} / \mathrm{m}^{2} / \mathrm{lx}$ sebagai ambang antara reflektivitas yang dapat diterima dan reflektifitas yang tidak dapat diterima pada program manajemen marka jalan yang baru [7]. Studi evaluasi umur dari marka jalan dengan model matematis diantaranya temuan model MC dimana model ini menghubungnkan reflektifitas dan umur marka jalan dengan kondisi lalu lintas [8], hubungan logaritmik antara reflektifitas dan usia, model linier berdasarkan umur dan volume lalu lintas [9], model prediksi untuk cat marka, model degradasi untuk menentukan sisa masa pakai, di mana parameter model yang mengimplementasikan struktur data dan prediksi model untuk memperkirakan kondisi aset pada setiap waktu di sistem jalan raya [10].

Studi di jalan federal FT005 di Selangor dan melibatkan pengecatan ulang marka jalan dengan material marka jalan termoplastik di sepanjang lokasi terpilih yang diidentifikasi. Pengumpulan data dilakukan pada siang dan malam hari. Temuan dari penelitian ini mengungkapkan bahwa terdapat interaksi yang signifikan antara jenis marka jalan dan waktu pengamatan terhadap posisi lateral kendaraan pada siang dan malam hari [11]. Taylor and Francis Group, LLC melakukan penelitian serupa untuk mengetahui performa reflektifitas marka jalan. Studi ini mengkaji pengaruh retoreflektifitas yang dilakukan dilapangan dengan simulasi hujan. Selama hujan, marka tertutup oleh air mengurangi retoreflektifitas dan mempengaruhi visibilitas marka pada malam hari[12].

Telah dibuktikan bahwa keselamatan jalan dapat ditingkatkan dengan meningkatkan kinerja visibilitas marka jalan. Hasil evaluasi menunjukkan bahwa marka jalan termoplastik dengan glass beads mengungguli sistem marka jalan lain yang diuji dalam hal reflektifitas. Peningkatan substansi reflektifitas dianggap sebagai faktor yang sangat menguntungkan untuk meningkatkan visibilitas pengemudi[13].

Sebuah pengujian dilakukan untuk mengembangkan prosedur evaluasi berbasis laboratorium yang dapat mengevaluasi dan mempelajari kinerja marka jalan dengan menirukan kondisi lalu lintas dan cuaca yang berbeda-beda. Terjadi penurunan sifat fisik yaitu reflektifitas, perubahan warna, dan daya tahan dari marka. Hasil mengilustrasikan bahwa kinerja secara logaritmik memburuk di bawah pembebanan yang berbeda, kecuali ketahanan marka termoplastik, yang mengikuti fungsi degradasi linier[14].

Marka jalan harus diganti setelah reflektifitas turun di bawah standar yang ditentukan. Penyelidikan terhadap perubahan reflektifitas dari waktu ke waktu terhadap marka thermoplastik pernah dilakukan antara Oktober 2005 sampai Juli 2007 ditemukan pola penurunan reflektifitas marka dari waktu ke waktu[15].

Studi lain mengembangkan database spasial-temporal dengan menggunakan data reflektifitas dan kecelakaan untuk mencoba mengukur hubungan antara tabrakan dan refleftifitas dari marka jalan. Nilai reflektifitas 200 $\mathrm{mcd} / \mathrm{m}^{2} / \mathrm{lx}$ atau kurang memiliki hubungan yang signifikan [16].

Penelitian ini bertujuan untuk meninjau degradasi reflektifitas marka jalan terhadap tipe permukaan jalan yang akan dilakukan perbaikan marka pada program pemeliharaan marka jalan rutin di Jalan Tol Ir. Wiyoto Wiyono, M.Sc sebagai bahan evaluasi operasional dan pemeliharaan operator jalan tol.

\section{Metode}

Penelitian ini dilakukan di Jalan Tol Ir. Wiyoto Wiyono, M.Sc pada ruas Cawang-Tanjung Priok (North South Link/NSL). Tol ini dibuat elevated karena di kolongnya ada jalan raya. Lokasi penelitian terletak pada JT 4B - JT 9B, lokasi ini ditentukan berdasarkan data sekunder dan hasil dari inspeksi rutin pengelola jalan tol Divisi Perencanaan dan Pemeliharann PT. Citra Marga Nusaphala Persada Tbk. Penelitian dilakukan secara eksperimental dengan membuat mock up. Material yang digunakan adalah marka jalan thermoplastik terdiri dari agregat, beads dan extender yang dicampur menjadi thermoplastik resin. Pengujian reflektifitas marka dilakukan dengan dua model mock up yaitu, pada JT 4B - JT 6B pembuatan mock up model uji I dengan penggelaran marka jalan di atas permukaan aspal langsung dan JT 7B - JT 9B pembuatan mock up model uji II dengan 
penggelaran marka di atas marka lama (overlay). Pengujian tingkat reflektifitas marka dilakukan pada malam hari. Pengujian reflektifitas marka jalan dilakukan pada lokasi eksisting dengan menggunakan alat reflektometer. Reflektometer akan bekerja memantulkan cahaya dimana cahaya dipantulkan dari permukaan dan dikembalikan ke sumber aslinya yang mensimulasikan kinerja retroreflektif marka jalan berupa tanda pada jarak $30 \mathrm{~m}$ di depan kendaraan (30 $\mathrm{m}$ geometry). Proses dari pembuatan mock up model benda uji dan metode pengujian di lokasi eksisting dengan langkah sebagai berikut:

a. Inspeksi pada lokasi penelitian.

b. Penentuan lokasi pengujian berdasarkan data sekunder dan hasil inspeksi.

c. Pembersihan lokasi yang akan di marka

d. Pembuatan pola marka sesuai kondisi geometrik untuk menentukan batas yang akan dilakukan pengujian

e. Pembuatan mock up (Model I) pada JT 4B - JT 6B dengan penggelaran marka jalan di atas permukaan aspal langsung. Pada tahap ini dilakukan pengupasan pada marka lama menggunakan Torch Gun sampai bersih.

f. Pembuatan mock up (Model II) pada JT 7B - JT 9B dengan penggelaran marka di atas permukaan marka lama (Overlay).

g. Marka yang sudah terpasang didiamkan selama 5-10 menit sebelum dilakukan pengujian reflektifitas

h. Pengujian reflektifitas pada hasil mock up (Model I).

i. Pengujian reflektifitas pada hasil mock up (Model II).

j. Hasil reflektifitas marka jalan terhadap dua kondisi pengujian.

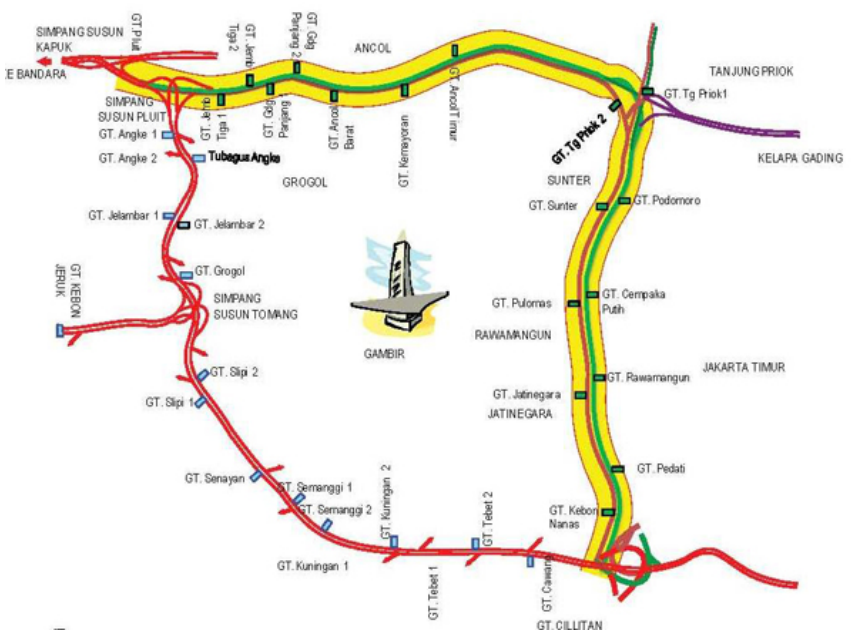

Gambar 1. Lokasi Penelitian Jalan Tol Ir. Wiyoto Wiyono

Material yang digunakan pada pengujian ini adalah marka jalan thermoplastic terdiri dari agregat (Filler) berwarna terang, pigmen, beads dan extender yang dicampur menjadi thermoplastik resin. Glass beads ditaburkan (on drop) maupun yang dicampurkan pada material cat yang disemprotkan guna membuat marka jalan reflektifitas atau dapat memantulkan cahaya. Komposisi campuran yang digunakan seperti terlihta pada Tabel 1.

Tabel 1. Campuran Bahan Thermoplastik[17]

\begin{tabular}{lll}
\hline Komponen & \multicolumn{2}{l}{ Warna Putih } \\
\hline Binder & $18 \%$ & Minimum \\
Glass Beads & $30-40 \%$ & \\
Titanium Dioxide & $10 \%$ & Minimum \\
Calcium Carbonate & $42 \%$ & Minimum \\
Filler & & \\
\hline
\end{tabular}

Pada penelitian ini untuk mengetahui reflektifitas marka jalan sesuai standar yang diisyaratkan dilakukan pengujian di lapangan. Marka jalan tol harus memiliki rata-rata tingkat reflektifitas minimal $300 \mathrm{mcd} / \mathrm{m}^{2} /$ lux pada usia $0-6$ bulan dan pada akhir tahun ke-1 rata-rata tingkat reflektifitas minimal $250 \mathrm{mcd} / \mathrm{m}^{2} /$ lux sesuai Permenhub RI Nomor: PM 26 tahun 2015. Alat uji yang digunakan Reflektometer Easylux.

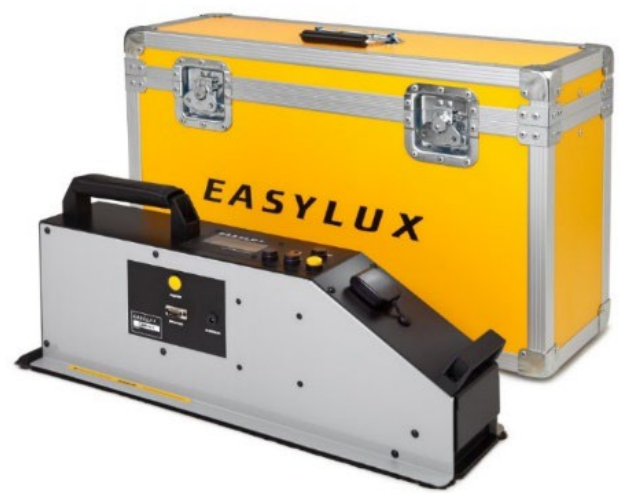

Gambar 2. Reflektometer Easylux

Kegiatan pemeliharaan marka jalan dilakukan dengan inspeksi terhadap marka jalan eksisting untuk mengamati perubahan yang terjadi selama masa layan baik pada pemeliharaan rutin maupun periodik. Inspeksi marka jalan dibutuhkan untuk mendapatkan jenis-jenis kerusakan yang terjadi pada marka sebagai dasar dalam program perbaikan yang akan di lakukan guna memenuhi standar pelayanan minimal yang telah ditetapkan

\section{Hasil dan Pembahasan}

Berdasar data hasil inspeksi lapangan di dapatkan jenis kerusakan yang paling banyak adalah marka jalan dengan jenis kerusakan pudar dengan jumlah 30 lokasi, jenis 
kerusakan lain seperti amblas, terhapus dan retak disebabkan oleh perkerasan aspal yang mengalami kerusakan. Jenis kerusakan yang terjadi selama masa pemeliharaan dapat dilihat pada Tabel 2.

Tabel 2. Jenis-Jenis Kerusakan Marka Jalan

\begin{tabular}{llll}
\hline No & Jenis Kerusakan & Jumlah & Satuan \\
\hline 1 & Pudar & 30 & Lokasi \\
2 & Terkelupas & 4 & Lokasi \\
3 & Amblas & 2 & Lokasi \\
4 & Terhapus & 2 & Lokasi \\
5 & Retak & 3 & Lokasi \\
\hline
\end{tabular}

Hasil inspeksi menunjukan jenis kerusakan marka jalan terkelupas terjadi pada marka chevron yang disebabkan peralatan perbaikan kendaraan pada saat mengalami kerusakan. Kerusakan dengan tingkat paling tinggi terjadi pada lokasi JT 4B - JT 9B yang akan di jadikan sebagai tempat untuk mock up.

Pembuatan mock up dilakukan dengan 2 model yaitu model pertama pada lokasi JT 4B - JT 6B dengan penggelaran marka jalan di atas permukaan aspal langsung. Pada model benda uji ini marka jalan eksisting dibersihkan dengan pengupasan melalui pembakaran menggunakan Torch Gun sampai bersih dan tidak ada marka jalan lama yang tersisa. Selanjutnya dilakukan pre marking sesuai geometri dan dilanjutkan dengan penggelaran marka baru. Pembuatan pada mock up model I dapat dilihat pada Gambar 3.

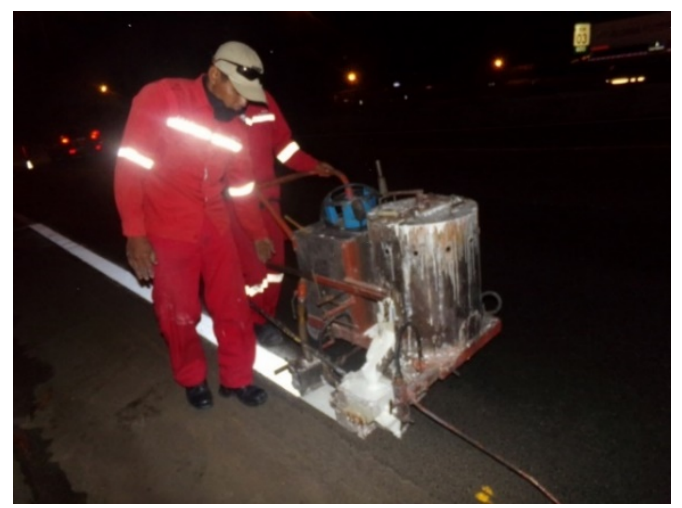

Gambar 3. Pembuatan Mock Up (Model I)

Pembuatan mock up ke dua pada JT 7B - JT 9B dengan metode penggelaran marka di atas marka lama yang dilakukan dengan teknik Overlay. Pada model benda uji ini marka eksisting hanya dibersihkan bagian permukaan terhadap debu dan partikel lainnya serta tidak dilakukan pengupasan pada marka lama. Marka yang memudar dicat kembali dengan mengikuti bekas marka lama. Pembuatan pada mock up model II dapat dilihat pada Gambar 4.

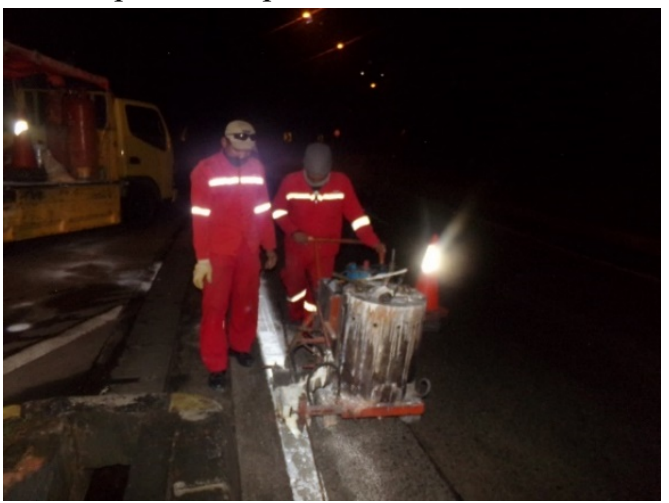

Gambar 4. Pembuatan Mock Up (Model II)

Perbaikan marka dilakukan pada lokasi eksisting yang telah mengalami kerusakan dengan tingkat reflektif rendah dibawah standar yang telah ditetapkan. Kedua model benda uji dibuat dan dilakukan pengukuran dalam waktu yang bersamaan untuk mengetahui tingkat reflektifitas marka jalan terhadap dua kondisi permukaan jalan yang berbeda. Pada perkerasan jalan yang sudah dioperasikan kegiatan peningkatan reflektifitas marka jalan atau pemeliharaan dilakukan dengan pelapisan ulang pada permukaan marka lama seperti mock up model II dengan teknik overlay. Secara umum sama seperti yang dilakukan pada pemeliharaan ruas Jalan Tol Ir. Wiyoto Wiyono, M.Sc pada pemeliharaan marka jalan rutin maupun marka jalan periodik.

Pengujian hasil mock up menggunakan alat reflektometer dapat dilihat pada gambar Gambar 5.

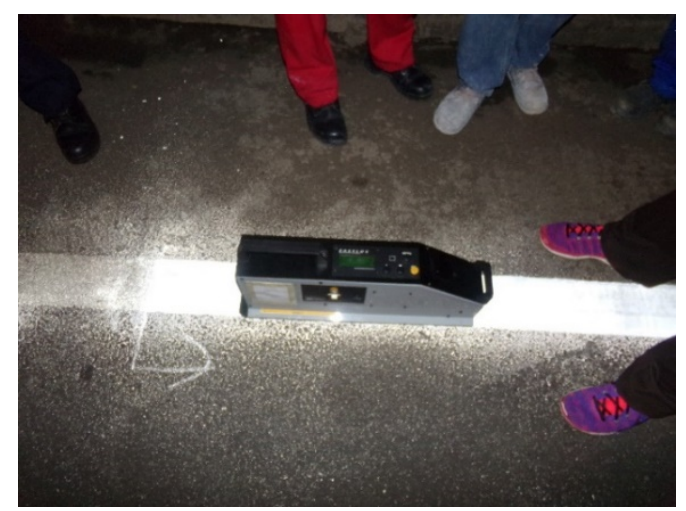

Gambar 5. Pengujian Reflektifitas Marka

Pengujian kondisi reflektifitas marka dilakukan pada kedua model benda uji untuk mengamati perbedaan tingkat reflektifitas dan prilaku material marka jalan thermoplastic terhadap kondisi yang berbeda. Pengujian tiap-tiap lokasi dilakukan sebanyak 9 titik dengan kombinasi pengujian 3 
titik di bagian awal, 3 titik di bagian tengah dan 3 titik di bagian akhir. Pembuatan mock up dan pengujian marka jalan dilakukan pada marka modul yang dilaksanakan pada malam hari untuk mendapatkan hasil yang lebih akurat.

Pendekatan menggunakan dua jenis model pengujian dilakukan untuk mengamati pengaruh dan perubahan nilai reflektifitas yang terjadi di lapangan secara langsung. Hasil pengujian reflektifitas marka jalan pada pengujian mock up model I dapat dilihat pada Tabel 3.

Tabel 3. Hasil Pengujian Reflektifitas Mock Up (Model I)

\begin{tabular}{ccccc}
\hline \multirow{2}{*}{ No } & \multicolumn{3}{c}{ Lokasi } & \multirow{2}{*}{ Keterangan } \\
\cline { 2 - 4 } & JT 4B & JT 5B & JT 6B & \\
\hline 1 & 756 & 751 & 741 & \\
2 & 751 & 751 & 750 & Awal \\
3 & 724 & 722 & 732 & \\
\hline 4 & 755 & 753 & 731 & \\
5 & 732 & 732 & 743 & Tengah \\
6 & 752 & 723 & 725 & \\
\hline 7 & 752 & 755 & 721 & \\
8 & 733 & 751 & 735 & Akhir \\
9 & 731 & 749 & 735 & \\
\hline
\end{tabular}

Berdasarkan pengujian yang dilakukan di dapatkan hasil reflektifitas maksimal $756 \mathrm{mcd} / \mathrm{m}^{2} / \mathrm{lux}$ dan reflektifitas minimal $721 \mathrm{mcd} / \mathrm{m}^{2} /$ lux dengan reflektifitas rata-rata 740 $\mathrm{mcd} / \mathrm{m}^{2} / \mathrm{lux}$.

Pengujian ke dua dilakukan pada mock up model II dari benda uji yang dibuat, yang membedakan adalah pada marka model II marka yang memudar langsung dicat kembali dengan mengikuti bekas marka lama. Hasil pengujian reflektifitas model II dapat dilihat pada Tabel 4. Hasil pengujian pada mock up model 2 yang dilakukan pada lokasi JT 7B - JT 9B didapatkan nilai reflektifitas maksimum $455 \mathrm{mcd} / \mathrm{m}^{2} / \mathrm{lux}$ dan reflektifitas minimum 401 dengan nilai rata-rata $424 \mathrm{mcd} / \mathrm{m}^{2} / \mathrm{lux}$.

Ditinjau secara teknis dari hasil pengujian nilai reflektifitas yang di dapatkan memenuhi standar minimal yang ditetapkan yaitu marka jalan tol harus memiliki rata-rata tingkat reflektifitas minimal $300 \mathrm{mcd} / \mathrm{m}^{2} / \mathrm{lux}$ [18].

Faktor-faktor yang mempengaruhi reflektifitas marka meliputi tipe permukaan jalan, volume kendaraan, dan elevasi jalan [19]. Penelitian sebelumnya menunjukan hasil bahwa volume lalu lintas berpengaruh terhadap umur pelayanan marka jalan [20] [21]. Pada penelitian ini dikembangkan dari penelitian sebelumnya yang menyebutkan tipe permukaan jalan mempengaruhi reflektifitas marka untuk membuktikan dan mengukur seberapa besar tipe permukaan mempengaruhi tingkat reflektifitas marka. Berdasarkan hasil pengujian, nilai reflektifitas rata-rata 740 $\mathrm{mcd} / \mathrm{m}^{2} / \mathrm{lux}$ pada mock up model I dan nilai rata-rata 424 $\mathrm{mcd} / \mathrm{m}^{2} / \mathrm{lux}$ pada mock up model II. Terdapat nilai selisih sebesar $316 \mathrm{mcd} / \mathrm{m}^{2} /$ lux sehingga didapatkan persentase sebesar $(316 / 740) \times 100=43 \%$, dengan demikian terjadi degradasi performa pada marka jalan benda uji model I terhadap benda uji model II sebesar $43 \%$. Hasil penelitian ini sesuai dengan pernyataan penelitian sebelumnya yang menyebutkan bahwa tipe permukaan jalan menjadi faktor yang mempengaruhi tingkat reflektifitas marka jalan. Dari hasil ini menunjukkan bahwa metode pemeliharaan marka jalan yang diterapkan pada Jalan Tol Ir. Wiyoto Wiyono, M.Sc tidak efektif. Ini menjadi penyebab terjadinya penurunan tingkat reflektifitas marka jalan dalam waktu singkat.

Tabel 4. Hasil Pengujian Reflektifitas Mock Up (Model II)

\begin{tabular}{ccccc}
\hline \multirow{2}{*}{ No } & \multicolumn{3}{c}{ Lokasi } & \multirow{2}{*}{ Keterangan } \\
\cline { 2 - 4 } & JT 7B & JT 8B & JT 9B & \\
\hline 1 & 421 & 411 & 421 & \\
2 & 430 & 421 & 412 & Awal \\
3 & 455 & 423 & 415 & \\
\hline 4 & 441 & 455 & 416 & \\
5 & 455 & 416 & 455 & Tengah \\
6 & 422 & 417 & 412 & \\
\hline 7 & 421 & 433 & 401 & \\
8 & 432 & 411 & 420 & Akhir \\
9 & 411 & 421 & 411 & \\
\hline
\end{tabular}

\section{Simpulan}

Tipe permukaan jalan mempengaruhi tingkat reflektifitas marka dengan hasil degradasi sebesar $43 \%$ pada metode penggelaran marka yang dilakukan langsung diatas marka lama. Pada pengujian marka jalan di atas permukaan aspal, material thermoplastik terhadap glass beads mengikat dengan sempurna sedangkan pada pengujian marka jalan di atas permukaan marka lama dengan teknik overlay material thermoplastik terhadap glass beads tidak mengikat dengan baik sehingga material glass beads mudah terlepas yang menyebabkan degradasi terhadap nilai reflektifitas marka. Penelitian selanjutnya diperlukan dengan mempertimbangkan pengaruh lingkungan terhadap penurunan nilai reflektifitas untuk hasil yang lebih komprehensif.

\section{Daftar Pustaka}

[1] C. Author, H. Sulistio, A. Wicaksono, and L. Djakfar, "The Prediction Models of Motorcycle Accidents on Surabaya Arterial Roads Using 
Generalized Linear Models," Middle-East J. Sci. Res., vol. 18, no. 12, pp. 1859-1866, 2013, doi: 10.5829/idosi.mejsr.2013.18.12.21519.

[2] H. Sulistio, A. Wicaksono, and L. Djakfar, "the Effect of Access Points on Motorcycle Accident Rates on Surabaya Arterial Roads," Aust. J. Basic Appl. Sci., vol. 8, no. July, pp. 38-43, 2014

[3] M. Machsus, R. Basuki, and A. F. Mawardi, "Generalized additive models for estimating motorcycle collisions on collector roads," Procedia Eng., vol. 125, pp. 411-416, 2015, doi: 10.1016/j.proeng.2015.11.105.

[4] Machsus, I. Prayogo, Chomaedhi, D. W. Hayati, and A. Utanaka, "Road safety analysis on Achmad Yani frontage road Surabaya," IOP Conf. Ser. Mater. Sci. Eng., vol. 267, no. 1, 2017, doi: 10.1088/1757$899 X / 267 / 1 / 012027$.

[5] Y. Oktopianto, S. Shofiah, F. A. Rokhman, and K. Pangestu, "Analisis Daerah Rawan Kecelakaan ( Black Site ) Dan Titik Rawan Kecelakaan ( Black Spot ) Provinsi Lampung," Borneo Eng. J. Tek. Sipil, vol. 5, no. 1, pp. 40-51, 2021, doi: 10.35334/be.v5i1.1777.

[6] Y. Oktopianto and D. W. Hidayat, "Reflectivity Analysis and Maintenance Program of Road Markings IR . WIYOTO WIYONO Toll Road," J. Adv. Res. Dyn. Control Syst., vol. 12, no. 02, pp. 3118-3122, 2020, doi: 10.5373/JARDCS/V12I2/S20201431.

[7] F. E. Loetterle, R. A. Beck, and J. Carlson, "Public perception of pavement-marking brightness," Transp. Res. Rec., 2000, doi: 10.3141/1715-08.

[8] D. Chimba, E. Kidando, and M. Onyango, "Evaluating the service life of thermoplastic pavement markings: Stochastic approach," J. Transp. Eng. Part B Pavements, 2018, doi: 10.1061/JPEODX.0000055.

[9] L. Ozelim and R. E. Turochy, "Modeling retroreflectivity performance of thermoplastic pavement markings in Alabama," J. Transp. Eng., 2014, doi: 10.1061/(ASCE)TE.1943-5436.0000661.

[10] W. E. Sitzabee, J. E. Hummer, and W. Rasdorf, "Pavement Marking Degradation Modeling and Analysis," J. Infrastruct. Syst., 2009, doi: 10.1061/(asce)1076-0342(2009)15:3(190).

[11] N. Aznirahani, M. Yunin, N. Sheda, M. Zulkiffli, A.
Shabadin, and S. Z. Ishak, "Effect of Enhanced Road Marking in Road Safety-Speed and Lateral Position," J. Built Environ., 2018.

[12] M. Hadi and P. Sinha, "Effect of pavement marking retroreflectivity on the performance of vision-based lane departure warning systems," J. Intell. Transp. Syst. Technol. Planning, Oper., 2011, doi: 10.1080/15472450.2011.544587.

[13] G. L. M. Leung, A. W. G. Wong, S. H. F. Wong, and S. You, "Study on wet visibility of road markings in Hong Kong," in Proceedings of the 21st International Conference of Hong Kong Society for Transportation Studies, HKSTS 2016 - Smart Transportation, 2018.

[14] M. Mohamed, A. Abdel-Rahim, E. Kassem, K. Chang, and A. G. McDonald, "Laboratory-Based Evaluation of Pavement Marking Characteristics," $J$. Transp. Eng. Part B Pavements, 2020, doi: 10.1061/jpeodx.0000168.

[15] D. B. Clarke and Y. Xuedong, "Retroreflectivity performance of 90-mil thermoplastic longitudinal pavement markings during the early application period," Adv. Transp. Stud., 2010.

[16] O. Smadi, R. R. Souleyrette, D. J. Ormand, and N. Hawkins, "Pavement marking retroreflectivity analysis of safety effectiveness," Transp. Res. Rec., 2008, doi: 10.3141/2056-03.

[17] PT. Citra Marga Nusaphala Persada, "Kerangka Acuan Kerja Pekerjaan Marka Jalan,” 2020.

[18] D. Lalu, L. Dan, and A. Jalan, "Peraturan Direktur Jenderal Perhubungan Darat Tentang," 2013.

[19] C. Debaillon, P. J. Carlson, H. G. Hawkins, Y. He, T. Schnell, and F. Aktan, "Review and development of recommended minimum pavement marking retroreflectivity levels," Transp. Res. Rec., 2008, doi: 10.3141/2055-09.

[20] V. Owusu, Y. A. Tuffour, D. A. Obeng, and M. Salifu, "Degradation of Retro-Reflectivity of Thermoplastic Pavement Markings: A Review," Open J. Civ. Eng., 2018, doi: 10.4236/ojce.2018.83023.

[21] P. Lertworawanich and A. Karoonsoontawong, "Service life analysis and maintenance program of pavement markings in Thailand," Transp. Res. Rec., 2012, doi: 10.3141/2272-14 